\title{
Conflitos e barreiras culturais à comunicação: uma pesquisa empírica em ecossistemas multiculturais
}

Conflicts and cultural barriers for communication: an empirical survey in multicultural environments

Conflictos y barreras culturales a la comunicación: una investigación en ambientes multiculturales

Felipe Chibás Ortiz

- Doutor em Ciências da Comunicação pela Escola de Comunicações e Artes da Universidade de São Paulo (ECA-USP)

- Mestre em Integração Latino-americana pela Universidade de São Paulo (Prolam-USP)

- Especialista em Marketing Direto pela Universidade Alcalá de Henares, Espanha

- Graduado em Psicologia pela Universidade de Havana (UH)

- Professor visitante de universidades do exterior

- Escritor, com dez livros publicados no Brasil, Canadá, Espanha e Cuba

- Ex-diretor da empresa Perfectu, representante da Global Estrategia, multinacional franco-espanhola de marketing digital e EAD presente em 15 países de 4 continentes

- Professor na ECA-USP

- E-mail: chibas_f@yahoo.es 


\section{ANO $11 \cdot$ NÚMERO 20 • 1ํSEM. 2014 - ORGANICOM \\ CONFLITOS E BARREIRAS CULTURAIS À COMUNICAÇÃO: UMA PESQUISA EMPÍRICA EM ECOSSISTEMAS MULTICULTURAIS}

\section{Resumo}

0 presente artigo descreve a pesquisa empírica sobre as barreiras culturais à comunicação realizada em quatro redes hoteleiras de diferentes origens sediadas no Brasil - norte-americana, francesa, mexicana e brasileira. Nela se objetiva verificar como os valores culturais nacionais, refletidos nos valores organizacionais específicos de cada país, têm uma influencia fundamental no perfil das barreiras culturais à comunicação. No trabalho se definem as barreiras culturais à comunicação diferenciando-as de outros tipos de barreiras. Este estudo se inscreve nos esforços por desenvolver pesquisa comparada de relações públicas internacionais. Utilizou-se o método de estudo de caso. Os resultados obtidos apontam para a influência dos valores nacionais e organizacionais no perfil das barreiras culturais à comunicação e na forma de solucionar os conflitos.

PALAVRAS-CHAVE: GESTÃO DA COMUNICAÇÃO • BARREIRAS CULTURAIS À COMUNICAÇÃO • CONFLITOS CULTURAIS • RELAÇÕES PÚBLICAS INTERNACIONAIS • GESTÃO DE RECURSOS HUMANOS.

\section{Abstract}

This article describes the empirical survey of the cultural barriers for communication conducted in four hotel chains of different origins that are established in Brazil (North-American, French, Mexican and Brazilian). In it one aims at verifying how the local cultural values, reflected in the specific organizational values of each country, have fundamental influence on the profile of the cultural barriers to communication. In the work one defines the cultural barriers to communication, differentiating them from other types of barriers. This study is included in the efforts to develop a comparative survey of international public relations. The case study method was used. The results obtained point towards the influence of the national and organizational values on the profile of the cultural barriers to communication and on the way of resolving conflicts.

KEYWORDS: COMMUNICATION MANAGEMENT • CULTURAL BARRIERS TO COMMUNICATION • CULTURAL CONFLICTS • INTERNATIONAL PUBLIC RELATIONS • HUMAN RESOURCES MANAGEMENT.

\section{Resumen}

En este artículo se describe la investigación empírica sobre las barreras culturales a la comunicación realizada en cuatro cadenas hoteleras de diferentes orígenes con sede en Brasil (americana, francesa, mexicana y brasileña). Su objetivo fundamental es comprobar cómo los valores culturales y organizacionales específicos de cada país, tienen una influencia decisiva en el perfil de las barreras culturales a la comunicación. En el trabajo se definen las barreras culturales a la comunicación. Este estudio se enmarca en los esfuerzos para desarrollar investigación comparada de Relaciones Públicas Internacionales. Se utilizó el método de estudio de caso. Los resultados apuntan la influencia de los valores nacionales y organizacionales influencia el perfil de las barreras culturales a la comunicación y la forma de resolver los conflictos. 
0

presente artigo é fruto da tese de doutorado defendida na Escola de Comunicações e Artes da Universidade de São Paulo (ECA-USP) (Chibás Ortiz, 2005) sob a orientação da Profa. Dra. Margarida M. Krohling Kunsch. Descreve uma pesquisa empírica que se inscreve nos esforços de aprofundamento no conhecimento de ferramentas que permitam gerir com maior precisão a comunicação organizacional nos mais diversos âmbitos, mas tentando também entender e valorizar a identidade comunicativa proveniente dos países das redes analisadas. Objetiva-se também contribuir para a compreensão da gestão da comunicação das relações públicas internacionais, eixo ainda pouco explorado dentro do universo das relações públicas (Grunig et al. 1995).

Entendemos por ambientes ou ecossistemas multiculturais de comunicação o hábitat e um conjunto de relações e redes de significados subjacentes que se criam como produto do convívio no mesmo espaço físico ou virtual de pessoas de origens e culturas diferentes. Os ecossistemas estudados estiveram localizados no âmbito hoteleiro. Por isso, a presente pesquisa deve ser expandida a outros ecossistemas organizacionais para verificar suas reais possibilidades de generalização.

Os hotéis, sobretudo os pertencentes a multinacionais, constituem verdadeiros ecossistemas de comunicação multicultural (Denker, 2003), pela confluência da cultura nacional dos funcionários do país no qual se encontram com a da cultura que trazem os representantes da matriz e a dos hóspedes. Estudar não apenas o potencial de comunicação multicultural que abrem as novas tecnologias e a globalização, mas também as dificuldades ou os problemas de comunicação, assim como as consequências que elas podem acarretar para a organização, é um caminho que deve ser trilhado se se deseja desenvolver as equipes de trabalho e as organizações.

Na pesquisa desenvolvida durante o mestrado (Chibás Ortiz, 2000) também sob a orientação da Profa. Dra. Margarida M. Krohling Kunsch, foram pesquisadas as relações existentes entre as barreiras à comunicação - administrativa, psicológica, física e semântica - e a criatividade organizacional, em hotéis brasileiros e cubanos. Essa pesquisa apontou que existiam um perfil de criatividade e um perfil de barreiras à comunicação, predominantes nas organizações de cada país. Levantamos então como hipótese que essas diferenças poderiam ter origem nas matrizes culturais diferentes existentes em cada país, razão pela qual aprofundamos esse aspecto na pesquisa aqui descrita, estudando organizações nacionais e multinacionais sediadas no Brasil, de quatro origens nacionais diferentes - brasileira, mexicana, norte-americana e francesa.

Oobjetivo principal deste artigoé mostrar a importância dosfatoresculturaisna compreensão da comunicação organizacional e a utilidade prática do conceito de barreiras culturais à comunicação para a gestão da comunicação nas organizações atuais, apresentando os principais resultados da pesquisa realizada a esse respeito. Consideramos as empresas estudadas, mesmo estando elas em solo brasileiro, como ecossistemas de comunicação internacional ou multicultural, dado o conjunto de culturas e subculturas que se reúnem no espaço de um hotel, principalmente os que integram grupos multinacionais.

\section{BARREIRAS CULTURAIS À COMUNICAÇÃO}

\section{Referencial teórico}

A significação da cultura dentro dos processos comunicacionais cresce dia após dia com o advento as novas tecnologias e a consequente construção de novas e complexas identidades híbridas pessoais e corporativas com várias camadas ou níveis 
(García Canclini, 2012; Straubhaar, 2013). Surgem assim novos atores sociais e se ressignificam os já existentes. Isso pode ser fonte de conflitos e barreiras culturais à comunicação.

Sobre as barreiras culturais à comunicação tem-se falado bastante, mas quase sempre de forma implícita e sem um aprofundamento sério através de pesquisa empírica. Paul Robbins (2002, p. 205) fala em barreiras de filtragem (quando a fonte manipula as informações para apresentá-las de uma forma mais atraente ao receptor); de percepção seletiva (quando 0 ser humano ouve e vê seletivamente, de acordo com suas necessidades e motivações); defensiva; e de linguagem (quando as mesmas palavras e frases têm significados diferentes para pessoas de diferentes sexos, idades, educação e formação cultural).

0 autor demonstra a existência de barreiras culturais à comunicação utilizando como exemplo o fato de um mesmo gesto poder ser compreendido de maneira muito diferente, dependendo da cultura do receptor. Chama atenção também para 0 fato de que pessoas que falam línguas diferentes percebem o mundo diferentemente, assim como as mesmas palavras têm significados diferentes em diferentes línguas e culturas e assim como existem línguas mais formais que outras. Peter Drucker (1989, p. 120) também se refere à importância das barreiras culturais à comunicação: "As mais importantes limitações na percepção são usualmente de ordem cultural e emocional e não de ordem física".

Adentrar as barreiras culturais à comunicação é, sem dúvida, um importante avanço e deve ser o início de uma nova etapa de pesquisas sobre a comunicação, vinculada à cultura, em um mundo cada vez mais interativo e globalizado. As pesquisas sobre barreiras à comunicação adquiriram hoje uma nova dimensão, dadas as novas exigências do mundo globalizado. Segundo Wilson Bueno (2004, p. 20),

\begin{abstract}
pouco a pouco as empresas vão descobrindo que a aquisição de congêneres no exterior e a formação de joint ventures não se resume a uma operação meramente financeira: quase sempre está em jogo um conflito cultural, no seu sentido mais amplo (diferenças de idioma, mas também na maneira de administrar o tempo, de desenvolver e manter relacionamentos, de exercer a liderança, de praticar a comunicação, etc.).
\end{abstract}

Robbins (2002, p. 205) refere-se também a diferenças relativas à entonação, que permitem a classificação dos idiomas em mais formais ou menos formais. No caso das barreiras de percepção, o autor chama a atenção para o fato de que pessoas que falam idiomas diferentes percebem o mundo de formas igualmente diferentes, assim como as mesmas palavras têm significados distintos em diferentes línguas e culturas. Como os esquimós percebem a neve de muitos modos diferentes, eles têm muitas palavras para ela.

Por isso, identificar as barreiras culturais à comunicação que podem estar interferindo nos processos organizacionais em geral e no modelo de relações públicas adotado mais especificamente pode resultar em mais um passo de avanço na compreensão das condições atuais sobre as instituições. Isso também permitirá conhecer mecanismos, estratégias, recursos, métodos e técnicas capazes de incentivar mudanças de maneira constante e adequada segundo as condições de cada local ou região.

A comunicação intercultural pode ser um elemento-chave para gerar boas condições de relacionamento, elevar os níveis de participação no interior dos grupos e das organizações, contribuir para a melhoria da qualidade de vida e diminuir as 
fontes de estresse, assim como para empregar os estados afetivos como um potente fator solucionador de problemas entre pessoas e em equipes que compartilham de identidades diferentes, em qualquer uma das complexas organizações atuais e, mais ainda, nas organizações hoteleiras.

As relações entre cultura nacional e organizacional e comunicação são um fato mais do que evidente e reconhecido por diferentes pesquisadores, mas a revisão bibliográfica mostra que pouco ou quase nada tem sido pesquisado sobre a relação entre os valores nacionais e organizacionais assumidos pelos indivíduos da organização e as barreiras à comunicação de origem cultural que eles podem ter. Embora explorada de forma insuficiente, essa é uma área de pesquisa essencial, pois as limitações numa dessas relações influenciam na dinâmica das outras, com importantes decorrências de ordem prática, podendo facilitar, dificultar ou mesmo impedir que determinada organização atinja os fins para os quais foi criada. Explicitar de maneira prática e perceptível tais relações é uma necessidade importante se o que se deseja é promover o aumento da eficiência e a qualidade de vida na organização.

Segundo Milton Oliveira (1997, p. 14), muitas organizações brasileiras estimulam a centralização, operam com procedimentos burocráticos, negam a autonomia e reforçam o medo e a competição interna, o que desestimula os processos de comunicação e criatividade em seu interior, mesmo quando o profissional ou trabalhador é muito criativo. Essa dinâmica é em grande parte determinada por fatores de ordem cultural. Desse modo, poderíamos perguntar: como superar ou contornar as barreiras culturais à comunicação e favorecer uma dinâmica interpessoal e grupal que estimule as pessoas a levarem para suas organizações toda a criatividade de que são capazes?

Além das barreiras à comunicação, podem existir outros tipos de elementos que a limitem. Segundo Hugh Culbertson (1996, p. 19), a discriminação a partir de padrões de comunicação baseados em relações de gênero, classe social, religião ou raça é um elemento a se levar em conta no planejamento da comunicação organizacional. Robbins (2002, p. 209) também faz referência a barreiras culturais, especificamente na comunicação entre homens e mulheres, no contexto de trabalho.

Entendemos por barreiras culturais à comunicação o conjunto de fatores, de ordem simbólica ou concreta, que vão além das diferenças idiomáticas e que podem dificultar a comunicação entre pessoas ou organizações de diferentes etnias, valores, países, povos, regiões ou culturas (Chibás Ortiz, 2005, p. 49).

Para definir os valores nacionais utilizamos a definição de Milton Rokeach (1973, p. 5), segundo a qual o valor "é uma crença duradoura em que um modo especial de conduta ou estado definitivo da existência é pessoal e socialmente preferível a um modo inverso ou oposto de conduta ou estado definido de existência". Essa definição serve para referendar tanto os valores nacionais como os organizacionais, sendo que os primeiros se referem a um país e os segundos, a um âmbito mais restrito de uma organização em particular (Tayeb, 1988).

Na Figura 1 se ilustra o funcionamento das barreiras à culturais à comunicação. 


\section{ANO $11 \cdot$ NÚMERO 20 • 1ํSEM. 2014 - ORGANICOM \\ CONFLITOS E BARREIRAS CULTURAIS À COMUNICAÇÃO: UMA PESQUISA EMPÍRICA EM ECOSSISTEMAS MULTICULTURAIS}

Figura 1 - Barreiras culturais à comunicação.

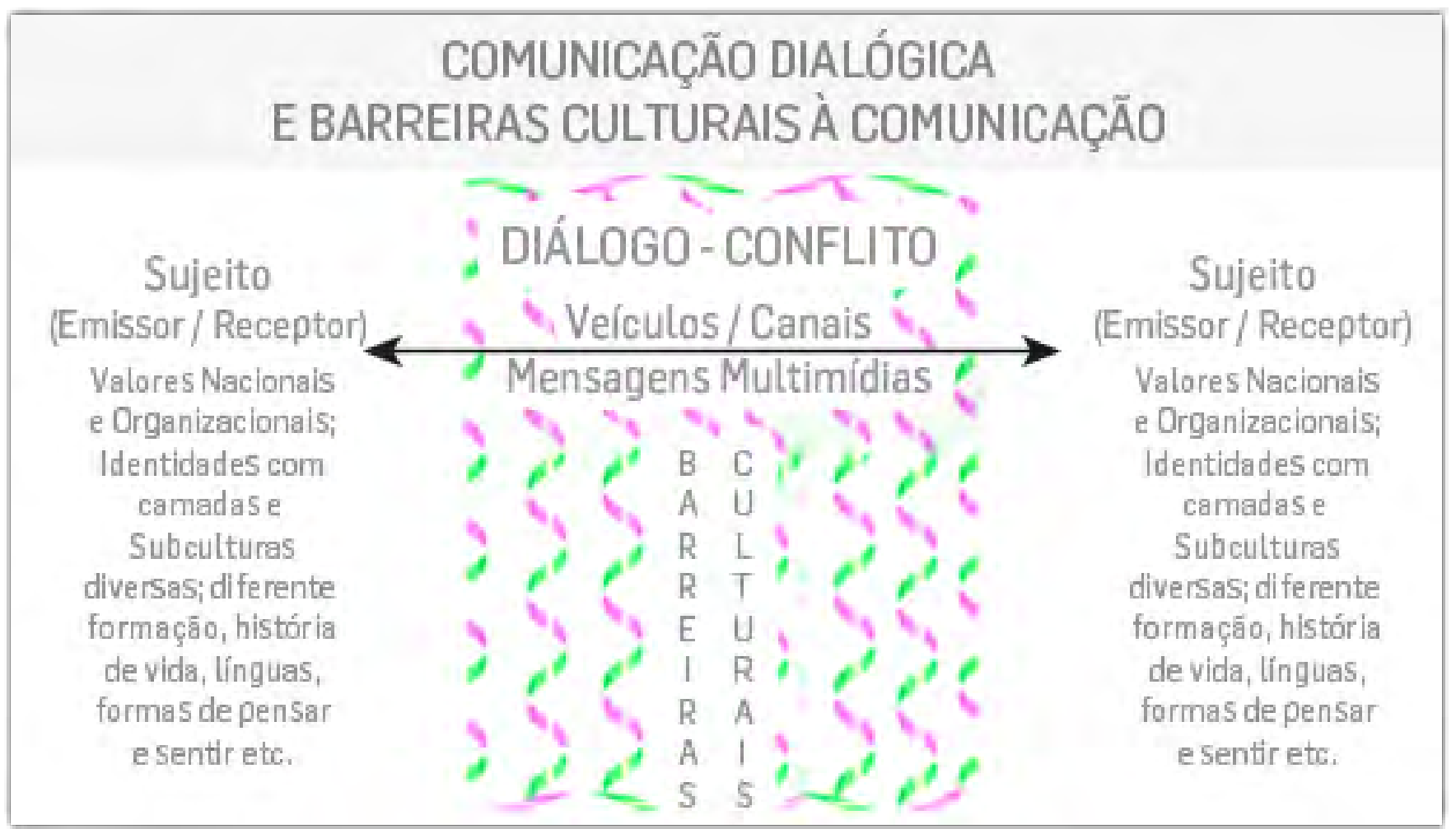

Fonte: Arquivo do autor.

\section{Procedimentos metodológicos}

0 problema de pesquisa levantado foi: quais são as dificuldades e as deficiências de origem cultural na comunicação que podem afetar a eficiência da comunicação organizacional em organizações hoteleiras, chamadas de barreiras culturais à comunicação. 0 objetivo geral foi identificar, analisar e descrever como os valores culturais nacionais, refletidos nos valores organizacionais específicos das organizações hoteleiras de cada país, influenciaram no perfil das barreiras culturais à comunicação presente em cada rede hoteleira e no modelo de relações públicas adotado. As questões de pesquisa que nortearam a investigação foram: Que relações existem entre os valores nacionais e organizacionais e as barreiras culturais à comunicação? Quais são as barreiras culturais mais importantes no processo de comunicação das organizações estudadas? Como as barreiras culturais à comunicação influenciam a vida organizacional e a interação com os públicos?

Realizou-se uma pesquisa quali-quantitativa de caráter exploratório. Adotou-se o método de estudo de caso e utilizaramse, como instrumentos para a coleta de dados, questionários quantitativos e qualitativos, a observação não-participante e entrevistas em profundidade, além do questionário e da escala de valores de Álvaro Tamayo (1994). A pesquisa esteve baseada na triangulação, ou no cruzamento, das informações obtidas através de várias técnicas (Yin, 2009).

Ela foi desenvolvida junto a hotéis de várias redes estrangeiras e uma brasileira, aplicando-se os instrumentos em dois hotéis de cada rede estudada. Foram pesquisadas a Accor, de origem francesa; a Atlantica, de origem norte-americana; a Posadas, que administra os hotéis de bandeira mexicana Caesar; e a Estanplaza, de origem brasileira. Esta última foi abordada para perceber como se manifestam os valores da cultura nacional e organizacional e a tipologia de barreiras culturais à comunicação sem a interferência direta de culturas estrangeiras.

Os instrumentos foram aplicados sempre com o gerente geral, o subgerente, o encarregado da comunicação ou de relações públicas; o gerente de recursos humanos; o chefe da recepção; e outros colaboradores que atendem diretamente o cliente. Participaram da pesquisa 15 colaboradores da rede Accor, 12 da Atlantica, 14 da Posadas e 12 da Estanplaza. Trabalhou-se com frequência e média simples de manifestação das barreiras culturais à comunicação, valores nacionais 
e organizacionais. Esses dados quantitativos, quando necessário, foram processados utilizando o teste de Tucker para a conformação de grupos de valores. Também se utilizou a análise de variância Anova para comprovar o nível de significação das diferenças nos valores coletados.

\section{BARREIRAS CULTURAIS ESTUDADAS}

Em geral, as barreiras apresentam dois polos - por exemplo, forte e fraco ou explícito e implícito - entre os quais se encontra todo um continuum de comportamentos. A seguir serão apresentadas as barreiras culturais à comunicação que estudamos nesta pesquisa. Sua formulação deriva de pesquisas anteriores realizadas por Hofstede (2003) e por Chibás Ortiz (2000). As barreiras culturais à comunicação estudadas foram:

1. Etnocentrismo - valorização extrema da origem do país ou estado da rede versus não-valorização;

2. Tendência ao individualismo/coletivismo - valorização extrema do pensamento e bem-estar individual versus valorização do pensamento e bem-estar coletivo;

3. Distância hierárquica - valorização excessiva dos cargos e da hierarquia organizacional versusnão valorização-desse fator;

4. Controle de incertezas - tendência a tentar planejar e controlar os fatos e a incerteza versus deixar acontecer;

5. Sexismo - tendência a valorizar mais o fator masculinidade em detrimento da feminilidade versus valorizar mais a feminilidade em detrimento da masculinidade;

6. Sensualismo - explícita ou implícita valorização de um belo corpo versus a não-valorização de um belo corpo como fator de sucesso;

7. Religiocentrismo - tendência a achar que só a minha religião está certa e as demais estão erradas versus tendência a aceitar a religião dos outros;

8. Internalidade/externalidade - tendência a pensar que a causa do sucesso ou insucesso é interna e está em mim versus tendência a achar que a causa do sucesso é externa, está fora ou nos outros;

9. Urbano ou rural - ter uma origem urbana é melhor que ter nascido num ambiente rural versus ter uma origem rural é melhor que ter nascido num ambiente urbano;

10. Relação distorcida com a ética - tendência a ter um respeito rígido pelas regras versustendência a não respeitar as regras;

11. Tendência a supervalorizar ou a não valorizar a idade - ter mais idade é melhor que ter menos versus ter menos idade é melhor que ter mais);

12. Adoção de estilos de comunicação autocráticos ou excessivamente laisser-faire-tendência a tomar todas as decisões autoritariamente versus deixar a equipe tomar as decisões e o líder deixar fazer tudo o que a equipe quiser; 
13. Imediato versus mediato - tendência a querer os resultados imediatamente versus tendência a querer os resultados no longo prazo.

O nível de expressão das barreiras culturais à comunicação refere-se ao grau em que elas se expressam: baixo, médio e alto. Esse grau foi avaliado a partir do número ou da frequência simples e do percentual com o qual foi mencionada a barreira cultural à comunicação pelos entrevistados.

\section{ANÁLISE DOS RESULTADOS}

\section{Barreiras culturais à comunicação}

O Quadro 1 apresenta a frequência da manifestação das barreiras culturais à comunicação nas redes hoteleiras pesquisadas.

Quadro 1 - Barreiras culturais à comunicação: frequência e percentual.

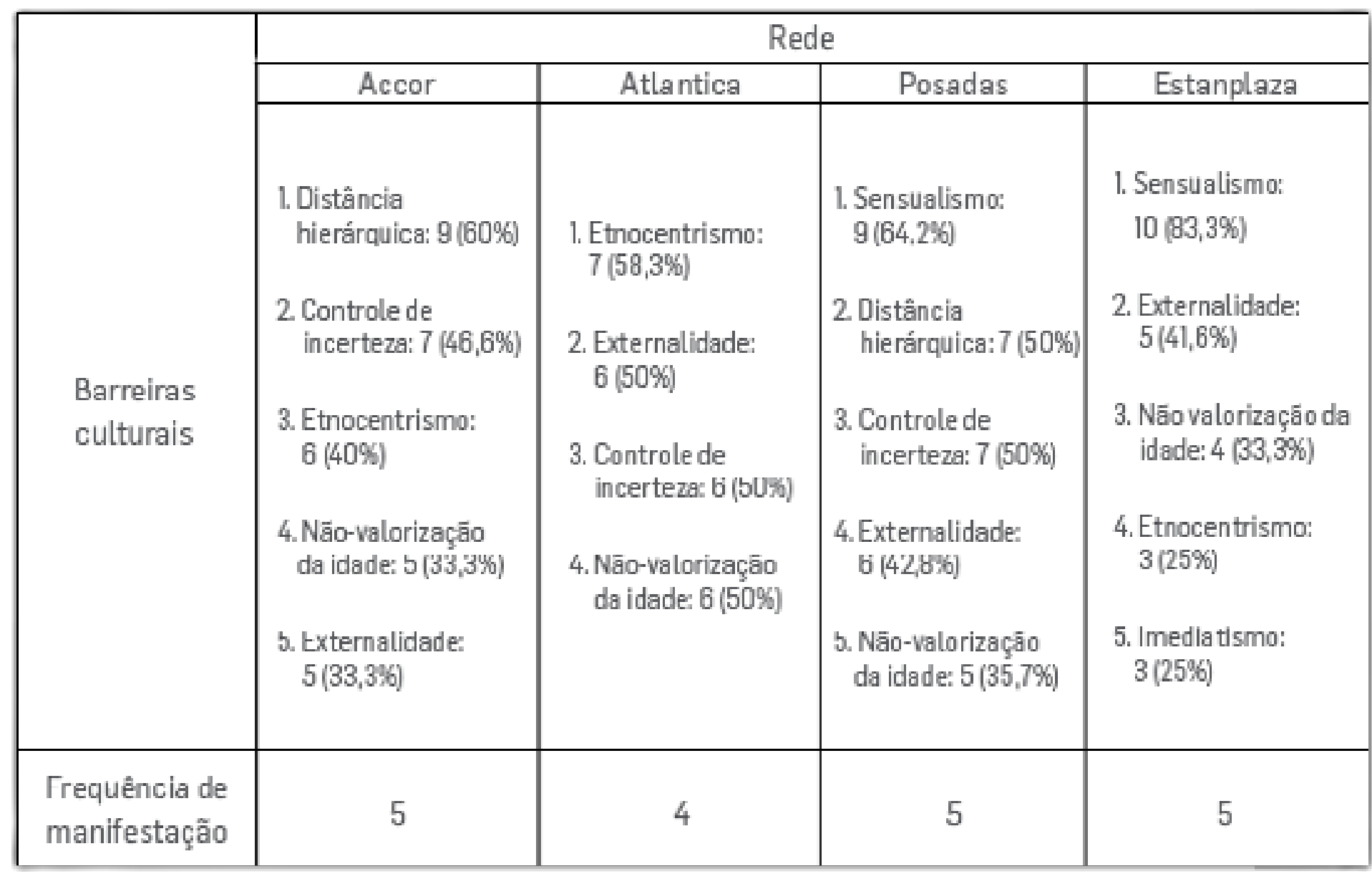

Fonte: Chibás Ortiz (2005).

Observou-se que todas as redes têm mais ou menos uma quantidade igual de barreiras culturais à comunicação, mesmo que o conteúdo varie de uma para outra. De maneira geral, uma barreira presente em todas as redes é a de internalidade/ externalidade, especificamente no polo externalidade. Isso significa que os participantes da pesquisa que trabalham nessas redes têm uma forte tendência a acreditar que o sucesso o insucesso de uma tarefa se deve a causas externas e não às suas próprias decisões e esforço. Culpam-se os outros pelo que deu errado.

Ainda que com uma frequência mais baixa que a anterior, também a barreira relativa à não-valorização da idade e da experiência se manifestou em todas as redes: isso coincide com o perfil demográfico dos entrevistados e aponta para resistências e limites na hora de contratar ou simplesmente de lidar com pessoas de faixas etárias acima dos 45 anos. 
A barreira cultural do controle da incerteza está presente em todas as redes estrangeiras, embora não na Estanplaza, de origem brasileira. Esse resultado coincide com os enunciados de Betânia Tanure Barros e Marco Aurélio Spyer Prates (1996, p. 52), para quem "o brasileiro não tenta controlar todas as situações".

Observa-se que o sensualismo está presente, e com uma intensidade elevada, como barreira cultural à comunicação apenas nas redes de origem latino-americana, Estanplaza e Posadas, respectivamente em 10 (83,3\% do total) e em 9 indivíduos (64,2\%). Isso sem dúvida tem a ver com nossas histórias e identidades específicas, sempre muito ligadas ao corporal e à valorização da sedução. Esse resultado coincide com a opinião de vários pesquisadores (Ferrari, 2000).

As barreiras que tiveram uma maior frequência de manifestação na rede Accor foram as de distância hierárquica - em 9 casos, ou $60 \%$ do total da rede - e controle de incertezas - em 7, ou 46,6\%. Isso pode ser causado pela existência de alguns valores do país da matriz, que são, de forma geral, próximos de representações sociais mais tradicionais como o respeito à hierarquia e às tradições e a valorização das normas estabelecidas. Esse resultado coincide com o de Ortiz (1991, p.127), segundo o qual o passado colonial, de reinado e de império, faz com que nessa cultura se valorizem mais as categorias hierárquicas e os rituais de etiqueta. Percebe-se nos organogramas da rede Accor uma organização piramidal com uma estrutura hierárquica bem delimitada. Esse tipo de estrutura reforça a presença da barreira da distância hierárquica, tanto na comunicação ascendente como na descendente.

O controle da incerteza como barreira cultural à comunicação pode ser causado nessa rede pela tendência a querer planejar o futuro e a controlar as situações imprevistas, segundo relataram 7 sujeitos, o que corresponde a 46,6\% do total da rede.

No caso da rede Atlantica, nota-se o peso da barreira etnocentrismo em 7 entrevistas, o que corresponde a 58,3\% de seus funcionários: isso pode ser causado porque, nessa rede, se tem a prática de ressaltar os valores e comportamentos típicos norte-americanos.

Como produto da observação, enxergamos em todos os hotéis pesquisados uma barreira que não se percebeu através dos dados dos questionários: a do sexismo. Isto é, ainda se privilegia e valoriza mais a comunicação proveniente de pessoas do sexo masculino, menosprezando-se a que provém do sexo feminino.

É necessário também analisar uma barreira que achamos de forma mais intensa nos hotéis da rede Estanplaza, mas que também se manifestou em outras redes: o etnocentrismo paulista, uma barreira cultural regional. Segundo alguns dos sujeitos entrevistados, os paulistas têm uma melhor visão da vida do que os outros brasileiros "porque trabalham mais, têm mais acesso a informações e oportunidades e são mais abertos".

A barreira da não-valorização da ética se manifestou de maneira indireta na rede Estanplaza, onde, entre os valores organizacionais de menor importância, se colocou a esperteza ou malandragem. Este valor está relacionado com o "jeitinho brasileiro" de obter as coisas pelo caminho das vantagens pessoais sem levar muito a sério as regras estabelecidas.

\section{Conflitos culturais}

Outro item de interesse ao analisarmos as relações entre as culturas é a presença ou não da comunicação intercultural e dos conflitos culturais. Os resultados obtidos foram resumidos no Quadro 2: 


\section{ANO 11 • NÚMERO 20 • 1은. 2014 - ORGANICOM \\ CONFLITOS E BARREIRAS CULTURAIS À COMUNICAÇÃO: UMA PESQUISA EMPÍRICA EM ECOSSISTEMAS MULTICULTURAIS}

Quadro 2 - Tipo de conflitos culturais por rede.

\begin{tabular}{|c|c|c|c|c|}
\hline \multirow{2}{*}{ Conflitos } & \multicolumn{4}{|c|}{ Rede } \\
\hline & Accor & Atlantica & Posadas & Estanplaza \\
\hline $\begin{array}{l}\text { Presença de conflitos } \\
\text { culturais - frequência } \\
\text { de manifestaçăa }\end{array}$ & $6(40 \%)$ & $7(58,3 \%)$ & $9(64 \%)$ & $4(33,3 \%)$ \\
\hline Tipo de conflito & $\begin{array}{l}\text { - Os franceses } \\
\text { valorizam a } \\
\text { hierarquia. } \\
\text { - Os franceses sắo } \\
\text { mais sérios e } \\
\text { objetivos } \\
\end{array}$ & $\begin{array}{l}\text { - Padronizaçắo } \\
\text { excessiva. } \\
\text { - Normas e } \\
\text { procedimentos da } \\
\text { matriz que năo se } \\
\text { ajustam ao Brasil } \\
\end{array}$ & $\begin{array}{l}\text { - Os mexicanos } \\
\text { enfrentam os } \\
\text { problemas de forma } \\
\text { rigida. }\end{array}$ & $\begin{array}{l}\text { - Pessoas } \\
\text { provenientes de } \\
\text { diferentes estados. } \\
\text { - Pessoas com } \\
\text { diferente nivel de } \\
\text { instruçăo. } \\
\end{array}$ \\
\hline $\begin{array}{c}\text { Forma de resolver os } \\
\text { conflitos }\end{array}$ & $\begin{array}{l}\text { - O estilo de } \\
\text { gerenciamento } \\
\text { inclui ética e } \\
\text { escutar as pessoas. } \\
\text { - Procurando os } \\
\text { superiores }\end{array}$ & $\begin{array}{l}\text { - Falar de forma clara e } \\
\text { aberta }\end{array}$ & $\begin{array}{l}\text { - Seguindo os manuais } \\
\text { de normas e } \\
\text { procedimentos. } \\
\text { - Procurando os } \\
\text { superiores. } \\
\text { - Aguarda-se a } \\
\text { orientaçăo da matriz. }\end{array}$ & $\begin{array}{l}\text { - Cada conflito se } \\
\text { resolve de maneira } \\
\text { diferente. } \\
\text { - Espera-se } \\
\text { orientaçắo da } \\
\text { matriz }\end{array}$ \\
\hline
\end{tabular}

Fonte: Chibás Ortiz (2005).

Os números naturais indicam a quantidade de participantes da pesquisa que mencionaram a existência de conflitos, e a porcentagem entre parênteses indica o percentual que isso representou. Destaca-se que a rede Posadas é a que enfrenta mais conflitos culturais (64\%) se comparada com as outras, segundo os informantes consultados, o que pode ter ocorrido por causa do número e tipo de barreiras culturais à comunicação que ela enfrenta. No caso da Estanplaza, que não é uma rede estrangeira, no lugar de se perguntar se existiam conflitos entre a cultura nacional e a estrangeira, proveniente da matriz, perguntou-se se existiam conflitos produzidos pela coexistência entre várias culturas regionais. Esses resultados são coerentes se comparados com os outros, dado que, como parece, a rede Posadas (Caesar) tem maiores dificuldades em se adaptar ao público brasileiro, adotando o modelo de relações públicas de "informação pública"l A Estanplaza é a que tem menos conflitos culturais, por ser uma rede nacional que conhece as diversas identidades culturais coexistentes no país, embora não esteja isenta deles por lidar com pessoas provenientes de diferentes regiões e com diferentes níveis de instrução.

Observa-se a existência de uma ampla gama de conflitos de origem cultural, que abarca desde a forma de gerenciar os recursos materiais e humanos até a forma de atender os hóspedes e se projetar no mercado. As soluções ou formas propostas para enfrentar os conflitos incluem todo um conjunto de perspectivas, embora algumas delas se repitam, como a de ouvir os superiores nas redes Accor e Posadas, onde dois dos valores nacionais e organizacionais mais importantes são a valorização das normas e a hierarquia.

Note-se que tanto na natureza do conflito descrito, quanto nas formas de enfrentá-lo estão inseridas as barreiras culturais à comunicação e os valores nacionais e organizacionais que predominam em cada rede. Assim, por exemplo, no caso das redes Accor e Posadas, a solução de ouvir os superiores contém, além dos valores descritos acima, a barreira cultural de distância hierárquica. Nessa mesma situação encontra-se a solução expressada pelos participantes da pesquisa das redes Posadas e Estanplaza: aguardar que a matriz decida o problema.

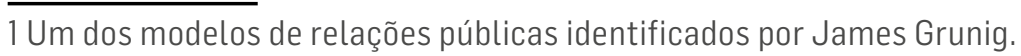




\section{ANO 11 • NÚMERO 20 • 1 SEM. 2014 - ORGANICOM \\ CONFLITOS E BARREIRAS CULTURAIS À COMUNICAÇÃO: UMA PESQUISA EMPÍRICA EM ECOSSISTEMAS MULTICULTURAIS}

De forma geral, percebe-se que o valor da flexibilidade, tipicamente brasileiro, entra em conflito com o valor da valorização das normas, que é muito importante para todas as redes estrangeiras. Na rede Estanplaza nota-se, também no caso da solução "resolver cada conflito de maneira diferente", a presença do valor da flexibilidade. Também é necessário dizer que, dadas as características e os valores do povo brasileiro, já antes descritas, como ser alegre, bem humorado e flexível, contornam-se muitos desses conflitos sem chegar ao extremo de um choque cultural para as partes envolvidas, como já foi destacado por outros autores (Farias, 2006).

\section{Inter-relações entre as variáveis}

Como síntese, bem como para mostrar as inter-relações entre os valores nacionais e organizacionais, e barreiras culturais à comunicação, apresentamos o Quadro 3.

Quadro 3 - Valores nacionais e os que a alta administração divulga nos hotéis e barreiras culturais: frequência de manifestação e percentual.

\begin{tabular}{|c|c|c|c|}
\hline Rede & $\begin{array}{c}\text { Valores nacionais do } \\
\text { país da rede } \\
\text { (frequência e percentual) }\end{array}$ & $\begin{array}{l}\text { Valores organizacionais } \\
\text { (escala ordinal) }\end{array}$ & $\begin{array}{c}\text { Barreiras culturais } \\
\text { à comunicação } \\
\text { (frequência e percentual) }\end{array}$ \\
\hline Accor (origem francesa) & $\begin{array}{l}\text { - Valorização das normas: } 9 \text { (60\%) } \\
\text { - Ética: } 8(53,3 \%) \\
\text { - Hierarquia: } 7(46,6 \%) \\
\text { - Respeito pelo ser humano: 5(33,3\%) }\end{array}$ & $\begin{array}{l}\text { - Hierarquia: 3,2 } \\
\text { - Qualificação de recursos } \\
\text { humanos: 3,7 } \\
\text { - Respeito ao funcionário: 3,7 } \\
\text { - Comprometimento: 4,3 }\end{array}$ & $\begin{array}{l}\text { - Distância hierárquica: } 9 \text { (60\%) } \\
\text { - Controle de incerteza: } 7 \text { (46,6\%) } \\
\text { - Etnocentrismo: } 6 \text { (40\%) } \\
\text { - Não-valorização da idade: } \\
5(33,3 \%) \\
\text { - Externalidade: } 5 \text { (33,3\%) } \\
\text { - Diferente nível de instrução: } \\
4(26,6 \%)\end{array}$ \\
\hline $\begin{array}{l}\text { Atlantica } \\
\text { (origem norte- } \\
\text { americana) }\end{array}$ & $\begin{array}{l}\text { - Valorização das normas: } 8 \text { (66,6\%) } \\
\text { - Afinidade pela nação } \\
\text { de origem: } 6 \text { (50\%) } \\
\text { - Apego aos números: } 6 \text { (50\%) } \\
\text { - Rapidez: } 6 \text { (50\%) } \\
\text { - Apego aos relatórios: } 5 \text { (41,6\%) } \\
\text { - Reconhecimento } \\
\text { individual: } 4 \text { (33,3\%) } \\
\text { - Apego as reuniões: } 4 \text { (33,3\%) }\end{array}$ & $\begin{array}{l}\text { - Comprometimento: 3,2 } \\
\text { - Maximização de lucros: 3,9 } \\
\text { - Competência: 3,9 } \\
\text { - Eficácia: 4,1 }\end{array}$ & $\begin{array}{l}\text { • Etnocentrismo: } 7 \text { (58,3\%) } \\
\text { • Externalidade: } 6 \text { (50\%) } \\
\text { • Controle de incerteza: } 6 \text { (50\%) } \\
\text { - Não-valorização da idade: } \\
6(50 \%)\end{array}$ \\
\hline $\begin{array}{c}\text { Posadas } \\
\text { (origem mexicana) }\end{array}$ & $\begin{array}{l}\text { - Valorização das normas: } 7 \text { (50\%\%) } \\
\text { - Desconfiança: } 7 \text { (50\%) } \\
\text { - Rapidez: } 7(50 \%) \\
\text { - Boa postura: } 4 \text { (28,5\%) } \\
\text { - Atendimento no padrão } \\
\text { norte-americano: } 3(21,4 \%)\end{array}$ & $\begin{array}{l}\text { - Eficácia: 3,1 } \\
\text { - Maximização de lucros: 3,3 } \\
\text { - Hierarquia: 3,5 } \\
\text { - Eficiência: 3,6 }\end{array}$ & $\begin{array}{l}\text { - Sensualismo: } 9 \text { (64,2\%) } \\
\text { - Distância hierárquica: } 7 \text { (50\%) } \\
\text { - Controle de incerteza: } 7 \text { (50\%) } \\
\text { - Externalidade: } 6 \text { (42,8\%) } \\
\text { - Não-valorização da idade: } \\
5(35,7 \%)\end{array}$ \\
\hline
\end{tabular}




\begin{tabular}{|c|c|c|c|}
\hline Rede & $\begin{array}{c}\text { Valores nacionais do } \\
\text { país da rede } \\
\text { (frequência e percentual) }\end{array}$ & $\begin{array}{l}\text { Valores organizacionais } \\
\text { (escala ordinal) }\end{array}$ & $\begin{array}{c}\text { Barreiras culturais } \\
\text { à comunicação } \\
\text { (frequência e percentual) }\end{array}$ \\
\hline $\begin{array}{c}\text { Estanplaza } \\
\text { (origem brasileira) }\end{array}$ & $\begin{array}{l}\text { - Flexibilidade: } 5(41,6 \%) \\
\text { - Espontaneidade: } 7(58,3 \%) \\
\text { - Hospitaleiro: } 4 \text { (33,3\%) } \\
\text { - Responsabilidade: } 4(33,3 \%) \\
\text { - Imitação do estrangeiro: } 3 \text { (25\%) }\end{array}$ & $\begin{array}{l}\text { - Qualificação de recursos } \\
\text { humanos: } 3 \\
\text { - Eficácia: } 3,1 \\
\text { - Competência: } 3,7 \\
\text { - Hierarquia: } 4,7\end{array}$ & $\begin{array}{l}\text { - Sensualismo: } 10(83,3 \%) \\
\text { - Externalidade: } 5(41,6 \%) \\
\text { - Não valorizam a idade: } 4(33,3 \%) \\
\text { - Etnocentrismo: } 3(25 \%) \\
\text { - Imediatismo: } 3(25 \%)\end{array}$ \\
\hline
\end{tabular}

Fonte: Chibás Ortiz (2005).

O Quadro 3 esclarece os vínculos entre as barreiras culturais à comunicação e os valores da cultura nacional e organizacional. Tudo parece indicar que existe uma relação entre essas três variáveis, que se explicita através de alguns exemplos. A rede Accor obteve um alto percentual na valorização das normas (9 pessoas das 15 entrevistadas, o que corresponde a 60\%), que por sua vez teve seu reflexo no valor organizacional da hierarquia e na barreira cultural da distância hierárquica (9 pessoas, equivalentes a 60\%). Este exemplo pode explicitar essa conexão. Outro caso pode ser como a afinidade pela nação de origem da rede (Estados Unidos) serve de plataforma para que se manifeste a barreira cultural do etnocentrismo presente nessa rede. Também na Atlantica o apego aos números e a rapidez podem ser os valores nacionais do país de origem da rede que podem estar por trás da externalidade como barreira cultural à comunicação: o apego ao número pelo número sem aprofundamentos e a procura pela quantificação a qualquer custo, sem a compreensão do que está por trás disso em meio à velocidade do serviço. Essa barreira, presente também nas outras redes, pode ser causada por outros valores. Assim, na Posadas a externalidade pode estar sendo causada pelo valor da boa postura, ligado à procura da boa aparência física e, portanto, também ao sensualismo, barreira cultural presente nessa rede. Na rede Estanplaza a externalidade pode estar vinculada ao valor da imitação do estrangeiro. Quando se pensa que alguém, por ser estrangeiro, possui alguma superioridade ou um dom a mais, já se está sendo superficial, conforme externado na análise. Isso acontece bastante no balcão dos hotéis.

Observa-se uma correspondência entre os valores nacionais mais importantes provenientes do país de origem da rede e os seus valores organizacionais mais significativos. Deveríamos destacar a relação existente entre as barreiras culturais à comunicação e os valores nacionais e organizacionais. Os valores nacionais seriam as causas ou alavancas que acionam as barreiras culturais à comunicação; estas últimas seriam uma manifestação comportamental daqueles. Mesmo assim, uma vez criadas as barreiras, e no eterno processo de interação humana, a manifestação de uma barreira, do ponto de vista comportamental, pode dar lugar, quando ocorre repetidas vezes, à formação de um valor associado.

\section{CONSIDERAÇÕES FINAIS}

Os resultados obtidos através do processamento dos dados mostraram que existe uma certa tendência a se relacionar de maneira consistente as barreiras culturais à comunicação e os valores nacionais e organizacionais. Ao que parece, os valores nacionais e organizacionais podem ser a causa da manifestação de determinadas barreiras culturais à comunicação.

A presença de barreiras culturais à comunicação - como a externalidade, o sexismo e a não-valorização da idade - é preocupante, dado que constituem, através dos departamentos de recursos humanos, uma forma de perpetuar mecanismos 
de relações sociais não condizentes com o momento atual. A relação entre as variáveis cultura e comunicação, sendo positiva, produz como resultado a comunicação inter e multicultural.

É necessário dizer que as diferenças e barreiras culturais observadas se expressam na comunicação verbal e escrita e também na não-verbal, através das músicas que são colocadas, de fotos e de logomarcas, de desenho e cores dos uniformes, das bebidas e dos alimentos que são oferecidos e do tipo de acolhida corporal, diferentes em cada caso. Isto com todos os públicos (interno, externo e misto) e segmentos de mercado.

Existem conflitos entre valores nacionais, organizacionais e regionais dentro das redes estudadas. Mediar esses conflitos ou evitar de forma preventiva que aconteçam pode ser outra das funções do profissional de relações públicas (Kunsch, 2003).

Foi possível observar que não existe rede ou organização hoteleira pura em termos de valores. Na verdade, elas são uma mistura ou um amálgama de valores diferentes, entre os quais destacam-se os valores do país de origem da rede e os do país no qual se encontra o empreendimento. Cada rede hoteleira faz uma mistura diferente dos valores da matriz com os valores típicos brasileiros. Mas é evidente que os valores nacionais e organizacionais permeiam toda a forma de gestão e estilo de trabalho dessas organizações, assim como o perfil das barreiras culturais à comunicação predominantes.

As redes hoteleiras internacionais, mesmo aquelas que mostraram muita vontade de se adaptar ao Brasil, não modificam seu estilo de gerenciamento, forma de solucionar os conflitos e os valores nacionais predominantes.

Emboraasbarreirasculturaisàcomunicaçãosejammanifestaçõesdevaloresnacionaiseorganizacionais, umamesmabarreira pode ter causas ou valores diferentes. As diferenças observadas no perfil de valores e barreiras culturais à comunicação de cada rede podem estar sendo causadas pela história, pela evolução e por culturas diferentes do país de origem das redes, 0 que acarreta diferentes formas de perceber a organização, a comunicação e as relações com os diversos públicos. Aprender a lidar com essas diferenças dentro de uma organização hoteleira implica o desenvolvimento de competências para a comunicação intercultural. É necessário que sejam desenvolvidas maneiras de agir organizacionalmente que respeitem e valorizem as diferenças culturais nacionais e regionais, utilizando-as como um fator de sucesso. Sugere-se também realizar pesquisas semelhantes à presente em outros tipos de ecossistemas.

Abordar as barreiras culturais à comunicação no universo atual é, sem dúvida, um importante avanço, que deve ser o início de uma nova etapa de pesquisas sobre a comunicação vinculada à cultura, em um mundo cada vez mais tecnológico, interativo e multicultural.

\section{REFERÊNCIAS}

BARROS, Betânia Tanure; PRATES, Marco Aurélio Spyer. O estilo brasileiro de administrar. São Paulo: Atlas, 1996.

BUENO, Wilson da Costa. Comunicação empresarial. São Paulo: Manole, 2003. 
CHIBÁS ORTIZ, Felipe. Barreiras culturais à comunicação e relações públicas em redes hoteleiras sediadas em São Paulo. 200 fl. Tese (Doutorado em Ciências da Comunicação) - Escola de Comunicação e Artes, Universidade de São Paulo. São Paulo, 2005.

Barreiras à comunicação e criatividade organizacional: um estudo em hotéis brasileiros e cubanos. Dissertação (Mestrado em Integração da América Latina) - Programa de Pós-Graduação em Integração da América Latina (Prolam), Universidade de São Paulo, 2000. 167 p.

CULBERTSON, Hugh. Introduction. In: CULBERTSON, Hugh; CHEN, Guo Ming (Org.). International public relations: a comparative analysis. London: Lawrence Eribaun, 1996. p. 234-267.

DENKER, Ada de Freitas Maneti. A abordagem científica na hospitalidade. In: DENKER, Ada de Freitas Maneti; BUENO, Marielys Siqueira (Org.). Hospitalidade: cenários e oportunidades. São Paulo: Thomson, 2003. p. 93-112

DRUCKER, Peter. A nova era da administração. São Paulo: Pioneira, 1989.

FARIAS, Luiz Alberto de. 0 que a comunicação pode (ou não) fazer na hora da crise? Idade Mídia, v. 1, p. 17-18, 2006.

FERRARI, Maria A parecida. A influencia dos valores organizacionais na determinação da prática e do papel dos profissionais de relações públicas: estudo comparativo entre organizações de Brasil e do Chile. Tese [Doutorado em Ciências da Comunicação) - Escola de Comunicações e Artes da Universidade de São Paulo (ECA-USP), 2000.

GARCÍA CANCLINI, Néstor. A sociedade sem relato: antropologia e estética da iminência. São Paulo: Edusp, 2012.

GRUNIG, James E. et al. Models of public relations in a international setting. Journal of Public Relations Research, v. 7, n. 3, p 163-187, 1995.

KUNSCH, Margarida, M. Krohling Planejamento de relações públicas na comunicação integrada. 4. ed. - rev., atual. e compl. São Paulo: Summus, 2003.

OLIVEIRA, Milton. Energia emocional, base para a gerência eficaz. São Paulo: Makron Books, 1997.

ORTIZ, Renato. Cultura e modernidade. São Paulo: Brasiliense, 1991.

ROBBINS, Stephen Paul. Comportamento organizacional. Rio de Janeiro: LTC, 2002.

ROKEACH, Milton. The nature of human values. New Jersey: Prentice Hall, 1973.

STRAUBHAAR, Joseph. Sedimentada, híbrida e múltipla? A nova geografia cultural das identidades. Matrizes, ECA-USP, v. 7 , n. 1, p. 59-93, 2013.

TAMAYO, Alvaro. Hierarquia de valores transculturais e brasileiros. Psicologia: teoria e pesquisa, v. 10, n. 2, p.269- 285, 1994. 
TAYEB, Monir H. Organizations and national culture: a comparative analysis. California: Sage, 1988.

YIN, Robert K. Case study research: design and methods. California: Sage, 2009.

Artigo recebido em 15.11.2013 e aprovado em 01.12.2013. 